\title{
CULTURAL HERITAGE AND INNOVATION
}

\author{
James B. Ang ${ }^{1}$ \\ ${ }^{1}$ Department of Economics, Nanyang Technological University, Singapore. \\ E-mail: James.Ang@ntu.edu.sg
}

\begin{abstract}
Cultural heritage is a major driver of behavioral, social, and economic norms in a society. This paper studies the relationship between culture and economic development by focusing on how individualism is related to technological innovation. It hypothesizes that individualistic people tend to have beliefs and views that emphasize the importance of innovation and creativity. Using individual-level data from the World Values Survey, the results provide some evidence in favor of this hypothesis.
\end{abstract}

Keywords: Technology; Innovation; Individualism.

JEL Classification: O30; Z10.

Article history:

Received : June 5, 2018

Revised : October 11, 2018

Accepted : October 19, 2018

Available online : October 31, 2018

https://doi.org/10.21098/bemp.v21i1.961 


\section{INTRODUCTION}

The idea that culture affects economic development can be traced back to the work of Weber (1930), who was among the first to articulate the relevance of an individualistic culture for long-run development by highlighting how the Protestant ethics of the Calvinists were a driving force for capitalism. Modern literature continues to echo the view that the individualism-collectivism cleavage plays an important role in explaining the differences in nationwide economic outcomes (see, e.g., Macfarlane, 1979; Greif, 1994; Lal, 1999; Mokyr, 2014).

In particular, the congruence between economic growth, innovation and technology adoption in individualistic societies has received much attention in the literature (Ball, 2001; Giuliano et al., 2006; Ashraf and Galor, 2007; Tabellini, 2008; Gorodnichenko and Roland, 2017). Among others, Triandis (1995, 2001) argues that individualism is the most significant driver of cultural disparity across countries that also has a significant influence on technology adoption. This paper is related to this strand of literature by establishing the relationship between innovation and individualism. Individual-level data on the perception of individualistic values and innovation are taken from the World Values Survey (WVS) to examine the association between individualism and innovation.

An individualistic society fosters values and societal norms where personal freedom and achievements are more highly emphasized than collective actions and interests. Hofstede (1980) defines individualism as "a preference for a looselyknit social framework in which individuals are expected to take care of only themselves and their immediate families". Studies by cross-cultural psychologists have established that individualistic societies do not encourage conformity of traditional values, but rather emphasize creativity and independent thinking. Such societies provide an environment that is conducive to scientific advancement and innovation. Independent ideas and personal achievements are lauded and rewarded through the award of social status and financial compensation (Gorodnichenko and Roland, 2011). This therefore provides psychological, social and financial incentives for invention that leads to greater scientific and technological advancement.

Based on these tenets, we hypothesize that individualistic societies tend to foster and encourage a psychological inclination towards innovation. The paper proceeds as follows. Section II provides an empirical investigation of our hypothesis. Section III concludes.

\section{EMPIRICAL ANALYSIS}

The following model is regressed to investigate the relationship between individualism and innovation:

$$
\text { Innovation }_{i}=\alpha+\beta I D V_{i}+c v_{i}^{\prime} \gamma+\varepsilon_{i}
$$

where Innovation captures an individual's inclination towards innovation, IDV is the degree of individualism, $c v^{\prime}$ is a vector of control variables, as described below, and $\varepsilon$ is an unobserved error term. 
We investigate the relationship between innovation and individualistic culture using individual-level data from the World Values Survey (WVS). In particular, we construct three measures of innovation and three indicators of individualism. The innovation measures are constructed based on the following questions. The first asks "whenever science and religion conflict, religion is always right". We assign a value of 0.5 if the respondents disagree and 1 if they strongly disagree. If they agree or strongly agree the values will be 0 . Hence, the resulting variable reflects the extent to which science is more credible than religion. We call this variable credibility of science. The second question asks the respondents to choose which of the following aspects are most important (i.e., their first choice): (a) a stable economy; (b) progress toward a less impersonal and more humane society; (c) progress toward a society in which ideas count more than money; and (d) the fight against crime. A value of 1 is assigned if the respondents choose (c) and 0 if they choose other answers. This variable is labelled as value of ideas in this study. The last question asks "are the tasks you perform at work mostly routine tasks or mostly creative tasks?" The answers can range from "mostly routine tasks" (1) to "mostly not routine tasks" (10). We divide the raw scores by 10 . The resulting variable captures the extent to which the tasks performed are creative, and hence we call this measure creative tasks.

We measure individualism by referring to three WVS variables capturing the respondents' beliefs and views on the importance of tradition, the justification of divorce, and the significance of family in an individual's life. Schwartz (1992, 1994) argues that collectivism is associated with tradition and conformity at the individual level. Individuals who value tradition seek to preserve the customary ways of doing things, and any changes make them uncomfortable. Individuals who value conformity abide by clear rules and structures, and prefer to do what they are told. Accordingly, we use relevant data from WVS to capture the non-tradition aspect of individualism. The first question asks the respondents to rate the degree to which the description of this person is similar to the respondents: "tradition is important to me; to follow the customs handed down by one's religion or family". It can take values from 1 to 6 with 1 being "very much like me" and 6 being "not at all like me". We divide this variable by 6 and call it non-tradition.

Next, Inglehart (1990) and Triandis (1995) argue that individualism emphasizes the pursuit of one's self-interest and hence individualists are less likely to give up their personal fulfillment to save an unhappy marriage. In their view, individualist societies tend to exhibit more favorable attitudes and are more tolerant towards divorce than collectivist societies. Empirical findings by Lester (1995) and Dion and Dion (1996) provide strong support for this view. Their results show that divorce rates are significantly correlated with a society's level of cultural individualism, with highly individualist societies exhibiting higher divorce rates. Hence, the second question we select prompts the respondent to rate to what extent they agree that divorce is justifiable. The answers can range from "never justifiable" (1) to "always justifiable" (10). We divide this variable by 10 and call it divorce justification.

Finally, Alesina and Giuliano (2010) use individual responses from the WVS regarding the role of the family to measure the power of family ties. They emphasize the role of the strength of family ties in influencing various economic 
outcomes. In particular, individuals who view their family as important in their life develop strong family ties, and this belief fosters the shaping of societies that are characterized by traditional family structures where the male is the bread winner whilst the female is dedicated to housework. This argument, along with those of Inglehart (1990) and Triandis (1995) above, suggests that societies with weak family ties tend to be more individualistic.

Accordingly, the third question assesses how important the family is in a person's life. It can take values from 1 to 4 with 1 being "very important" and 4 "not at all important". We assign a value of 0 to answers which indicate that family is "very important" or "rather important", 0.5 to "not very important" and 1 to "not at all important". This variable is labelled as family unimportance for the purpose of our study.

All regressions include age, age squared, marital status, gender, educational attainment (primary, secondary or tertiary), and income (low, middle or high) as control variables. Country fixed effects are included throughout. In addition, robust standard errors clustered by region are employed. Sources and description of all variables used in the estimations are presented in Table 1.

\section{Table 1.}

\section{Sources and Description of Variables}

This table describes the variables and their sources. Column 1 notes the name of the variable, column 2 has descriptions while the final column contains the sources of data.

\begin{tabular}{|c|c|c|}
\hline Variable & Description & Source \\
\hline \multicolumn{3}{|c|}{ [A] Proxies for Individualism } \\
\hline Non-Tradition & $\begin{array}{l}\text { A proxy for individualism based on WVS survey question } \\
\text { (V79) "Please listen to each description and tell me how much } \\
\text { each person is or is not like you: Tradition is important to this } \\
\text { person." The answers range from "(1) very much like me" to } \\
\text { "(6) Not at all like me". The raw scores are divided by } 6 \text { to } \\
\text { construct the variable. }\end{array}$ & WVS Database (2014) \\
\hline $\begin{array}{l}\text { Divorce } \\
\text { Justification }\end{array}$ & $\begin{array}{l}\text { A proxy for individualism based on the WVS survey question } \\
\text { (V205) "Justifiable: Divorce". The answers range from "(1) } \\
\text { Never justifiable" to "(10) Always justifiable". The raw scores } \\
\text { are divided by } 10 \text { to construct the variable. }\end{array}$ & WVS Database (2014) \\
\hline $\begin{array}{l}\text { Family } \\
\text { Unimportance }\end{array}$ & $\begin{array}{l}\text { A proxy for individualism based on the WVS survey question } \\
\text { (V4) "Importance in life: Family". The answers range from } \\
\text { "(1) Very important" to "(4) Not at all important". A value of } \\
0 \text { is assigned to answers which indicate that family is "very } \\
\text { important" or "rather important", } 0.5 \text { to "not very important" } \\
\text { and } 1 \text { to "not at all important". }\end{array}$ & WVS Database (2014) \\
\hline
\end{tabular}

\section{[B] Proxies for Innovation}

Credibility of

Science
A proxy for innovation based on the WVS survey question WVS Database (2014) (V153) "Whenever science and religion conflict, religion is always right". The answers range from "(1) Strongly agree" to "(4) Strongly disagree". A value of 0.5 is assigned if the respondents disagree and 1 if they strongly disagree. If they agree or strongly agree the values is 0 . 
Table 1.

\section{Sources and Description of Variables (Continued)}

This table describes the variables and their sources. Column 1 notes the name of the variable, column 2 has descriptions while the final column contains the sources of data.

\begin{tabular}{|c|c|c|}
\hline Variable & Description & Source \\
\hline Value of Ideas & $\begin{array}{l}\text { A proxy for innovation based on the WVS survey question } \\
\text { (V64) "Most important (First choice)". The answers offer } \\
\text { the following options "(1) a stable economy"; "( } 2 \text { ) progress } \\
\text { toward a less impersonal and more humane society"; "( }(3) \\
\text { progress toward a society in which ideas count more than } \\
\text { money"; and "(4) the fight against crime". A value of } 1 \text { is } \\
\text { assigned if the respondents choose (3) and } 0 \text { if they choose } \\
\text { other answers. }\end{array}$ & WVS Database (2014) \\
\hline Creative Tasks & $\begin{array}{l}\text { A proxy for innovation based on the WVS survey question } \\
\text { (V232) "Nature of tasks: routine vs. creative". The answers } \\
\text { range from "(1) mostly routine tasks" to "(10) mostly not } \\
\text { routine tasks". The raw scores are divided by } 10 \text { to construct } \\
\text { the variable. }\end{array}$ & WVS Database (2014) \\
\hline \multicolumn{3}{|c|}{$\begin{array}{c}\mathrm{C}] \text { Control Variables } \\
\end{array}$} \\
\hline Age & The respondent's age. & WVS Database (2014) \\
\hline Marital Status & The marital status of the respondent. & WVS Database (2014) \\
\hline Gender & The gender of the respondent. & WVS Database (2014) \\
\hline $\begin{array}{l}\text { Educational } \\
\text { Attainment }\end{array}$ & The respondent's highest level of education attained. & WVS Database (2014) \\
\hline Income & The respondent's income level. & WVS Database (2014) \\
\hline
\end{tabular}

Table 2 reports the estimation results using an OLS estimator. Consistent with our predictions, the results in columns (1) to (3) indicate that non-tradition, divorce justification, and family unimportance are positively and significantly correlated with credibility of science. The results are consistent when the dependent variable is replaced by value of ideas in columns (4) to (6). Estimates in the last three columns indicate that creative tasks is significantly correlated with non-tradition and divorce justification, but is uncorrelated with family unimportance. Overall, the results based on WVS data are consistent with our hypothesis, suggesting that individualism is positively correlated with innovation outcomes.

Table 2.

\section{OLS Individual-Level Estimates Based on World Value Survey Data (Full Sample)}

This table reports regression results. The standard errors are clustered at the region level. The coefficients are standardized beta coefficients. Symbols *** and *** indicate significance levels at the $10 \%, 5 \%$ and $1 \%$, respectively. All regressions include age, age squared, marital status, gender, educational attainment (primary, secondary or tertiary), and income (low, middle or high) as control variables. An intercept and country fixed effects are included throughout.

\begin{tabular}{lccccccccc}
\hline \multirow{2}{*}{$\begin{array}{l}\text { Dependent } \\
\text { Variable is: }\end{array}$} & $\mathbf{( 1 )}$ & $\mathbf{( 2 )}$ & $\mathbf{( 3 )}$ & $\mathbf{( 4 )}$ & $\mathbf{( 5 )}$ & $\mathbf{( 6 )}$ & $\mathbf{( 7 )}$ & $\mathbf{( 8 )}$ & $\mathbf{( 9 )}$ \\
\cline { 2 - 9 } & $\begin{array}{c}\text { Credibility } \\
\text { of Science }\end{array}$ & $\begin{array}{c}\text { Credibility } \\
\text { of Science }\end{array}$ & $\begin{array}{c}\text { Credibility } \\
\text { of Science }\end{array}$ & $\begin{array}{c}\text { Value of } \\
\text { Ideas }\end{array}$ & $\begin{array}{c}\text { Value of } \\
\text { Ideas }\end{array}$ & $\begin{array}{c}\text { Value of } \\
\text { Ideas }\end{array}$ & $\begin{array}{c}\text { Creative } \\
\text { Tasks }\end{array}$ & $\begin{array}{c}\text { Creative } \\
\text { Tasks }\end{array}$ & $\begin{array}{c}\text { Creative } \\
\text { Tasks }\end{array}$ \\
\hline Non-Tradition & $0.11^{* * *}$ & & & $0.02^{* * *}$ & & & $0.03^{* * *}$ & & \\
& $(13.34)$ & & & $(3.29)$ & & & $(3.92)$ & \\
Divorce Justification & & $0.11^{* * *}$ & & & $0.02^{* * *}$ & & & $0.02^{* * *}$ & \\
& & $(11.72)$ & & & $(4.01)$ & & & $(3.71)$ & \\
\hline
\end{tabular}


Table 2.

\section{OLS Individual-Level Estimates Based on World Value Survey Data (Full Sample) (Continued)}

This table reports regression results. The standard errors are clustered at the region level. The coefficients are standardized beta coefficients. Symbols ${ }^{*}{ }^{* *}$ and ${ }^{* * *}$ indicate significance levels at the $10 \%, 5 \%$ and $1 \%$, respectively. All regressions include age, age squared, marital status, gender, educational attainment (primary, secondary or tertiary), and income (low, middle or high) as control variables. An intercept and country fixed effects are included throughout.

\begin{tabular}{lccccccccc}
\hline \multirow{2}{*}{$\begin{array}{l}\text { Dependent } \\
\text { Variable is: }\end{array}$} & $\mathbf{( 1 )}$ & $\mathbf{( 2 )}$ & $\mathbf{( 3 )}$ & $\mathbf{( 4 )}$ & $\mathbf{( 5 )}$ & $\mathbf{( 6 )}$ & $\mathbf{( 7 )}$ & $\mathbf{( 8 )}$ & $\mathbf{( 9 )}$ \\
\cline { 2 - 10 } & Credibility Science & $\begin{array}{c}\text { Credibility } \\
\text { of Science }\end{array}$ & $\begin{array}{c}\text { Credibility } \\
\text { of Science }\end{array}$ & $\begin{array}{c}\text { Value of } \\
\text { Ideas }\end{array}$ & $\begin{array}{c}\text { Value of } \\
\text { Ideas }\end{array}$ & $\begin{array}{c}\text { Value of } \\
\text { Ideas }\end{array}$ & $\begin{array}{c}\text { Creative } \\
\text { Tasks }\end{array}$ & $\begin{array}{c}\text { Creative } \\
\text { Tasks }\end{array}$ & $\begin{array}{c}\text { Creative } \\
\text { Tasks }\end{array}$ \\
\hline Family & & & $0.03^{* * *}$ & & & $0.01^{* * *}$ & & & 0.01 \\
Unimportance & & & $(4.64)$ & & & $(3.01)$ & & & $(0.03)$ \\
\hline R-squared & 0.382 & 0.382 & 0.376 & 0.019 & 0.019 & 0.019 & 0.124 & 0.123 & 0.123 \\
Observations & 70490 & 69992 & 71043 & 74923 & 74220 & 75657 & 62564 & 62045 & 63224 \\
No. of Countries & 57 & 59 & 59 & 56 & 56 & 56 & 57 & 57 & 57 \\
No. of Districts & 749 & 749 & 750 & 744 & 743 & 744 & 750 & 749 & 750 \\
Controls & Yes & Yes & Yes & Yes & Yes & Yes & Yes & Yes & Yes \\
Country Dummies & Yes & Yes & Yes & Yes & Yes & Yes & Yes & Yes & Yes \\
\hline
\end{tabular}

Next, we provide evidence based on analyses that consider only data of the U.S. Using the U.S. data serves two important purposes. First, the U.S. is not only the most individualistic country in our sample, but also the world technological frontier in many respects. It is therefore crucial to understand whether individualism has the potential to explain preferences for innovation across individuals in one of the most innovative and individualistic countries in the world. Second, using data only for the U.S. enables us to control for a range of factors such as institutions, geography, language, and history that vary dramatically across countries. The resulting estimates, which are less affected by these factors, may provide useful evidence to complement the estimates based on full sample.

Table 3.

\section{OLS Individual-Level Estimates Based on World Value Survey Data (United States Only)}

This table reports regression results. The standard errors are clustered at the region level. The coefficients are standardized beta coefficients. Symbols ${ }^{*}{ }^{* *}$ and ${ }^{* * *}$ indicate significance levels at the $10 \%, 5 \%$ and $1 \%$, respectively. All regressions include age, age squared, marital status, gender, educational attainment (primary, secondary or tertiary), and income (low, middle or high) as control variables. An intercept and country fixed effects are included throughout.

\begin{tabular}{lccccccccc}
\hline \multirow{2}{*}{$\begin{array}{l}\text { Dependent } \\
\text { Variable is: }\end{array}$} & $\mathbf{( 1 )}$ & $\mathbf{( 2 )}$ & $\mathbf{( 3 )}$ & $\mathbf{( 4 )}$ & $\mathbf{( 5 )}$ & $\mathbf{( 6 )}$ & $\mathbf{( 7 )}$ & $\mathbf{( 8 )}$ & $\mathbf{( 9 )}$ \\
\cline { 2 - 11 } & $\begin{array}{c}\text { Credibility } \\
\text { of Science }\end{array}$ & $\begin{array}{c}\text { Credibility } \\
\text { of Science }\end{array}$ & $\begin{array}{c}\text { Credibility } \\
\text { of Science }\end{array}$ & $\begin{array}{c}\text { Value of } \\
\text { Ideas }\end{array}$ & $\begin{array}{c}\text { Value of } \\
\text { Ideas }\end{array}$ & $\begin{array}{c}\text { Value of } \\
\text { Ideas }\end{array}$ & $\begin{array}{c}\text { Creative } \\
\text { Tasks }\end{array}$ & $\begin{array}{c}\text { Creative } \\
\text { Tasks }\end{array}$ & $\begin{array}{c}\text { Creative } \\
\text { Tasks }\end{array}$ \\
\hline Non-Tradition & $0.27^{* * *}$ & & & 0.01 & & & $0.06^{* * *}$ & & \\
& $(35.39)$ & & & $(1.61)$ & & & $(7.89)$ & & \\
Divorce Justification & & $0.25^{* * *}$ & & & 0.01 & & & $0.07^{* * *}$ & \\
& & $(31.04)$ & & & $(1.58)$ & & & $(8.15)$ & \\
Family Unimportance & & & $0.04^{* * *}$ & & & 0.01 & & & $(0.01)$ \\
& & & $(5.26)$ & & & $(0.75)$ & & & $(-1.31)$ \\
\hline R-squared & 0.102 & 0.092 & 0.033 & 0.007 & 0.007 & 0.007 & 0.133 & 0.132 & 0.129 \\
Observations & 14973 & 14828 & 15091 & 16627 & 16452 & 16838 & 15333 & 15186 & 15507 \\
Controls & Yes & Yes & Yes & Yes & Yes & Yes & Yes & Yes & Yes \\
\hline
\end{tabular}


The results reported in Table 3 indicate that in five out of nine cases we find evidence supporting the notion that individualistic people tend to value the importance of innovation more. In cases where the coefficients for the proxies of individualism are statistically significant, their sizes are larger than those found in Table 1, which uses data for all countries. These findings highlight that individualism matters for the perception regarding the importance of innovation and creativity, even within a country that has achieved a very high level of technological sophistication.

\section{CONCLUSION}

Technology and innovation play a pivotal role in the economic growth of a country. Scientific advancement can account for the differences in incomes across countries (Hall and Jones, 1999; Mokyr, 2005; Aghion and Howitt, 2007; Comin et al., 2008; Comin and Hobijn, 2010). A major policy agenda for all nations in the world, therefore, is to promote the advancement of scientific inventions and innovation. It is a priority for most governments to create and foster an environment that will help bolster technological growth. Understanding the cultural dynamics that affect innovation is potentially useful for creating an environment conducive to scientific innovation.

This paper studies the relationship between individualism and innovation. An individual-level analysis is done to discern how individual values, beliefs and norms can collectively shape societal perceptions and priorities towards technological innovation. Our results show that individualism is positively correlated with innovation. Hence, consistent with our hypothesis, we conclude that individualistic people tend to possess beliefs and views that value the importance of innovation and creativity.

\section{REFERENCES}

Aghion, P., \& Howitt, P. (2007). Capital, Innovation, and Growth Accounting. Oxford Review of Economic Policy, 23, 79-93.

Alesina, A., \& Giuliano, P. (2010). The Power of the Family. Journal of Economic Growth, 15, 93-125.

Ashraf, Q., \& Galor, O. (2007). Cultural Assimilation, Cultural Diffusion, and the Origin of the Wealth of Nations. CEPR Working Paper No 6444.

Ball, R. (2001). Individualism, Collectivism, and Economic Development. Annals of the American Academy of Political and Social Science, 573, 57-84.

Comin, D., \& Hobijn, B. (2010). 'An Exploration of Technology Diffusion' . American Economic Review, 100, 2031-2059.

Comin, D., Hobijn, B., \& Rovito, E. (2008). Technology Usage Lags. Journal of Economic Growth, 13, 237-256.

Dion, K. K., \& Dion, K. L. (1996). Cultural Perspectives on Romantic Love. Personal Relationships, 3, 5-17.

Giuliano, P., Spilimbergo, A., \& Tonon, G. (2006). Genetic, Cultural, and Geographical Distances. IZA Discussion Papers, 2229. 
Gorodnichenko, Y., \& Roland, G. (2011). Individualism, Innovation, and LongRun Growth. Proceedings of the National Academy of Sciences of the United States, 108, 21316-21319.

(2017). Culture, Institutions, and the Wealth of Nations. Review of Economics and Statistics, 99, 402-416.

Greif, A. (1994). Cultural Beliefs and the Organization of Society: A Historical and Theoretical Reflection on Collectivist and Individualist Societies. Journal of Political Economy, 102, 912-950.

Hall, R. E., \& Jones, C. I. (1999). Why Do Some Countries Produce So Much More Output Per Worker Than Others? Quarterly Journal of Economics, 114, 83-116.

Hofstede, G. (1980). Culture's Consequences: International Differences in Work-Related Values. Beverly Hills CA: Sage Publications.

Inglehart, R. (1990). Culture Shift in Advanced Industrial Society. Princeton, NJ: Princeton University Press.

Lal, D. (1999). Unintended Consequences: The Impact of Factor Endowments, Culture, and Politics on Long-Run Economic Performance. Cambridge, MA: MIT Press.

Lester, D. (1995). Individualism and Divorce. Psychological Reports, 76, 258.

Macfarlane, A. (1979). The Origins of English Individualism. New York: Cambridge University Press.

Mokyr, J. (2005). Long-Term Economic Growth and the History of Technology. Handbook of Economic Growth, eds. P. Aghion and S. Durlauf (Amsterdam: North-Holland), 1113-1180.

(2014). Culture, Institutions, and Modern Growth. Institutions, Property Rights, and Economic Growth: The Legacy of Douglass North eds. S. Galiani and I. Sened. Cambridge: Cambridge University Press, 151-191.

Schwartz, S. H. (1992). Universals in the Content and Structure of Values: Theoretical Advances and Empirical Tests in 20 Countries. Advances in Experimental Social Psychology, ed. M. P. Zanna. San Diego, CA: Academic Press, 1-65.

(1994). Beyond Individualism and Collectivism: New Cultural Dimensions of Values. Individualism and Collectivism: Theory, Method, and Applications eds. U. Kim, H. C. Triandis, C. Kagitcibasi, S.-C. Choi and G. Yoon. Newbury Park, CA: Sage, 85-122.

Tabellini, G. (2008). Presidential Address: Institutions and Culture. Journal of the European Economic Association, 6, 255-294.

Triandis, H. C. (1995). Individualism and Collectivism. Boulder, CO: Westview. (2001). Individualism-Collectivism and Personality. Journal of Personality and Social Psychology, 69, 907-924.

Weber, M. (1930). The Protestant Ethic and the Spirit of Capitalism. London: Routledge. WVS Database. (2014). World Value Survey Wave 6 (2010-2014). World Values Survey Association (www.worldvaluessurvey.org). Madrid, Spain. 